\title{
Nutrition guidelines for undergraduate medical curricula: a six-country comparison
}

This article was published in the following Dove Press journal:

Advances in Medical Education and Practice

17 February 2015

Number of times this article has been viewed

\author{
Jennifer Crowley' \\ Lauren Ball ${ }^{2}$ \\ Celia Laur ${ }^{3}$ \\ Clare Wall' \\ Bruce Arroll ${ }^{4}$ \\ Phillippa Poole ${ }^{5}$ \\ Sumantra Ray ${ }^{3}$ \\ 'Discipline of Nutrition, School \\ of Medical Sciences, Faculty of \\ Medical and Health Sciences, The \\ University of Auckland, Auckland, New \\ Zealand; ${ }^{2}$ Centre for Health Practice \\ Innovation, Griffith University, Gold \\ Coast, QLD, Australia; ${ }^{3}$ Need for \\ Nutrition Education/Innovation \\ Programme, Medical Research \\ Council Human Nutrition Research, \\ Cambridge, UK; ${ }^{4}$ Department of \\ General Practice and Primary Health \\ Care, ${ }^{5}$ Department of Medicine, \\ Faculty of Medical and Health \\ Sciences, University of Auckland, \\ Auckland, New Zealand
}

Correspondence: Jennifer Crowley Discipline of Nutrition, School of Medical Sciences, Faculty of Medical and Health Sciences, The University of Auckland, Private Bag 92019, Auckland II42, New Zealand

Tel +649 3737599 ext 86355

Fax +649373750I

Email jcro057@aucklanduni.ac.nz
Aim: To assess nutrition curriculum guidelines for undergraduate medical education in the United States, Canada, the United Kingdom, Republic of Ireland, Australia, and New Zealand to highlight potential opportunities for shared learning on the advancement of nutrition in medical education.

Methods: A comprehensive list of professional bodies, councils, organizations, and other groups relevant to education or nutrition was compiled for each country after a review of relevant white and gray literature. All documents that were published from 2000 onwards, and that provided guidance on nutrition education within undergraduate medical education for one of the identified countries were included in the review. Each curriculum guideline was evaluated for 1) the organization's or group's role in undergraduate medical education; 2) the extent of nutrition-related recommendations; and 3) mandatory implementation.

Results: In the countries reviewed, a total of six nutrition-related curriculum guidelines were identified. All countries, aside from the Republic of Ireland, currently have externally visible curriculum guidelines to inform medical schools in undergraduate nutrition education, yet there is little evidence of mandatory enforcement. Curriculum guidelines predominantly focus on basic nutrition principles, nutrition assessment, the role of nutrition in health, interdisciplinary teamwork, and the provision of nutrition counseling. Notable differences exist regarding the scope and detail of curriculum guidelines for the reviewed countries.

Conclusion: There are promising developments in nutrition curriculum guidelines for medical schools within the reviewed countries. Differences in the scope and detail of nutrition curriculum guidelines may influence the nutrition education provided to medical students, and the subsequent nutrition care provided by doctors in these countries. Consideration is required as to how to monitor and evaluate the nutrition competence of doctors in relation to routine health care practices, as well as the impact of their competency levels on patients' nutrition behavior and health outcomes.

Keywords: medical education, nutrition, undergraduate, doctors, curriculum guidelines

\section{Introduction}

Undergraduate medical education aims to provide a foundation for the practice of junior doctors and for further training in any branch of medicine. ${ }^{1}$ Medical education curricula are continually reviewed to incorporate improvements in pedagogies and assessment, advancements in medical science, and future demands of the medical workforce. Medical schools may be informed by curriculum guidelines, but they generally have relative autonomy when determining learning activities, assessments, and endpoint competencies. ${ }^{1}$ Undergraduate curriculum guidelines are typically developed by professional associations or interest groups to have a specialized focus on 
an area of medicine or health (for example, palliative care, ${ }^{2}$ psychology $y^{3}$, and they provide an indication of the competence of graduating medical students in a given area.

Advancements in undergraduate curriculum guidelines have occurred internationally in the field of nutrition, following reiteration that it is within the responsibility of doctors to address nutrition-related issues concerning patients and the public. ${ }^{4}$ Nutrition curriculum guidelines stem from the recognized importance of nutrition in optimal health, ${ }^{5}$ and widespread reports of insufficient nutrition education during medical training. ${ }^{6-8}$ The expectation on doctors to provide nutrition care is increasing due to the rising prevalence of nutrition-related diseases ${ }^{9}$ and patients' preference to receive nutrition care from doctors rather than other health professionals. ${ }^{10}$ In order to provide effective nutrition care, doctors need knowledge of basic sciences related to nutrition, skills in nutritional assessment and counseling, and attitudes that are conducive to providing nutrition care when appropriate. ${ }^{11}$ In recognition of the role of nutrition in optimal health, ${ }^{9}$ a range of nutrition curriculum guidelines have been developed in the past two decades and generally focus on issues of clinical nutrition, undernutrition, and overnutrition across all age groups. ${ }^{12-14}$ Collectively, these guidelines represent opportunities for shared learning among comparable countries to progress the advancement of nutrition in undergraduate medical education.

Shared learning in medical education is facilitated through comparable tertiary education systems, continuing medical education programs, language of delivery, and the health care needs of populations. The US, Canada, the UK, the Republic of Ireland, Australia, and New Zealand are comparable in these key areas, and they may therefore be expected to have similar nutrition curriculum guidelines. Of note, an "International Summit" on medical nutrition education within these six countries will be hosted by the Need for Nutrition Education/Innovation Programme (NNEdPro) in Cambridge, UK, in $2015 .{ }^{15}$ The purpose of the summit is to: 1 ) share information on the current state of medical nutrition education in each country; 2) identify shared needs in medical nutrition education; 3) showcase examples of transferable models of nutrition education; and 4) identify opportunities for joint strategies in medical nutrition education. As a forerunner to the summit, an investigation of the similarities and differences among existing guidelines for these countries may inform the future development of national or international guidelines in medical nutrition education, along with strategies to support doctors in the provision of nutrition care to patients. Therefore, the aim of this review was to assess, compare, and contrast existing nutrition curriculum guidelines for undergraduate medical education in the USA, Canada, the UK, the Republic of Ireland, Australia, and New Zealand to highlight potential opportunities for shared learning on the advancement of nutrition in medical education.

\section{Methods}

This review utilized a systematic approach to identify undergraduate nutrition curriculum guidelines from the USA, Canada, the UK, Ireland, Australia, and New Zealand. A comprehensive list of professional bodies, councils, organizations, and other groups relevant to education or nutrition was compiled for each country after a review of relevant literature. The literature included peer-reviewed journal articles (white literature) and reports from professional organization Websites (gray literature). Databases used included MEDLINE ${ }^{\circledR}$ and PubMed using the search terms "nutrition curriculum" and "undergraduate medical nutrition education" and "curriculum policy". All documents that were published from 2000 onwards, and that provided guidance on nutrition education within undergraduate medical education for one of the identified countries were included in the review. Each curriculum guideline was evaluated for 1) the organization's or group's role in undergraduate medical education; 2 ) the extent of nutrition-related recommendations; and 3) mandatory implementation. Countries were grouped according to commonalities in geographical location, medical education accreditation, and reciprocity between nations. Information on nutrition curriculum guidelines were extracted independently by two reviewers (JC and LB) and disagreements were resolved through consultative and iterative discussion among the authors.

\section{Results}

Curriculum guidelines from nine committees were found. Three curriculum guidelines were not assessed because updated versions have been published since 2000. Table 1 presents six curriculum guidelines developed to inform medical schools regarding undergraduate nutrition education.

\section{US and Canada}

Standards for medical education in both the USA and Canada are set by the Liaison Committee on Medical Education (LCME). Medical schools must be accredited by the LCME, and are informed by a series of curriculum guidelines developed and published by the Association of American Medical Colleges (AAMC) under the generic heading Tomorrow's Doctors, Tomorrow's Cures. ${ }^{16}$ Nutrition concepts are a key 


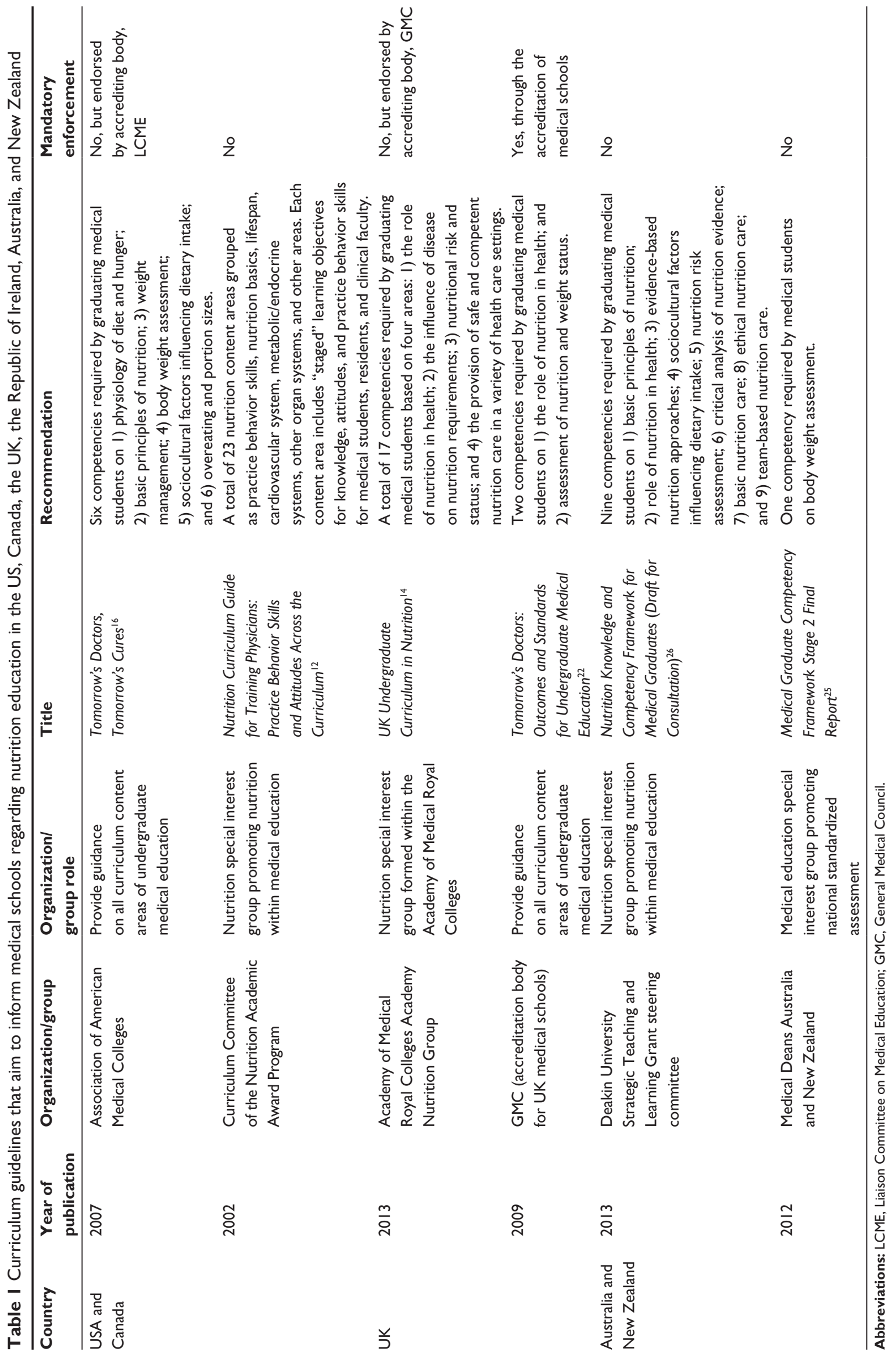


focus of one set of guidelines for the prevention and treatment of overweight and obesity, including six nutrition knowledge and assessment competencies. ${ }^{16}$

In addition to the AAMC guidelines, other guidelines regarding medical nutrition education exist in the USA. The importance of enhancing medical nutrition education was first identified at a national level in $1985,{ }^{17}$ reinforced in $1990,{ }^{18}$ and supported by the American Medical Student Association in $1996 .{ }^{13}$ These milestones culminated in the formation of the Nutrition Academic Awards from 1998 to 2005. The aim of the Nutrition Academic Awards was to improve nutrition education for medical students, ${ }^{19}$ and it included the development of a nutrition curriculum guide. ${ }^{12}$ The curriculum guide includes 23 content areas with learning objectives for knowledge, attitudes, and practice behavior skills across medical specialties. Each objective is "staged" for medical students, residents, and clinical faculty, respectively. Concurrent to these events, expert nutrition interest groups reviewed and updated the US Medical Licensing Examination (USMLE) between 1997 and 2006 to increase the quantity and appropriateness of items included in the nutrition subscore for USMLE Step 1, 2, and 3 examinations. ${ }^{20}$

Two recent initiatives illustrate how the inclusion of nutrition in medical education continues to develop in the USA. In 2012, the National Heart, Lung, and Blood Institute convened a group of interdisciplinary nutrition education experts to develop proactive approaches to nutrition education for health professionals. ${ }^{21}$ In addition, in 2013, the New York Academy of Sciences convened a workshop to discuss reforming nutrition science curricula throughout medical training, including 13 presentations by leading experts in medical nutrition education. ${ }^{21}$

\section{UK and Republic of Ireland}

Standards for medical education in the UK are set by the General Medical Council (GMC). The GMC determines standards for knowledge, skills, and behaviors that graduating medical students are required to demonstrate. Medical schools are accredited by the GMC, and are informed by the curriculum guidelines, Tomorrow's Doctors: Outcomes and Standards for Undergraduate Medical Education. ${ }^{22}$ The most recent edition (2009) includes two specific competencies relating to the role of nutrition in health and nutritional assessment. The GMC has also endorsed more expansive recommendations by the Academy Nutrition Group under the Academy of Medical Royal Colleges (UK and Ireland), which includes 17 comprehensive nutrition competencies based on nutrition in normal health, nutrition in public health, impact of nutrition on disease, impact of disease on nutrition, nutritional assessment, and nutrition care. ${ }^{14}$

Standards for medical education in the Republic of Ireland are set by The Medical Council. The Medical Council utilizes the World Federation for Medical Education's (WFME) Standards in Basic Medical Education. ${ }^{23}$ These standards do not specify requirements for nutrition education, and no other undergraduate nutrition guidelines have been identified.

\section{Australia and New Zealand}

Standards for medical education in Australia and New Zealand are set by the Australian Medical Council (AMC). Australian and New Zealand medical schools are accredited by the AMC, and are informed by AMC curriculum guidelines. ${ }^{24}$ Notably, the 90 curriculum guidelines of the AMC do not include specific nutrition competencies, although they do stipulate broad competencies involving common and important conditions, population health, and clinical and professional skills. ${ }^{24}$ The Medical Deans Australia and New Zealand completed a competencies project in 2014 to inform all medical schools in undergraduate education. ${ }^{25}$ Nutrition is briefly mentioned within one attribute and its related learning outcome for the management of common health conditions, as well as within the procedural skills recommended for assessing nutrition-related clinical conditions - specifically, measuring the height, weight, and body mass index of adults and children. The proposed assessment items (eg, Objective Structured Clinical Examinations [OSCEs]) do not specifically mention nutrition-related issues commonly seen in practice (eg, malnutrition, lifestyle-related chronic disease, and obesity), highlighting the opportunity for further incorporation of nutrition-related issues (eg, as cases and stations in OSCEs).

Recently, a curriculum framework to inform Australian medical schools in nutrition education was developed. The framework outlines four nutrition knowledge goals and five nutrition skill goals for medical students, as well as associated learning outcomes. The framework is aligned with the competencies developed by the Medical Deans Australia and New Zealand, ${ }^{26}$ and signifies ongoing work in this area.

\section{Discussion}

This paper assessed nutrition curriculum guidelines for undergraduate medical education in the USA, Canada, the UK, the Republic of Ireland, Australia, and New Zealand to highlight potential opportunities for shared learning on the advancement of nutrition in medical education. Overall, promising developments in nutrition guidelines for medical schools 
have taken place within the countries reviewed. Most countries currently have curriculum guidelines to inform medical schools in nutrition education, which generally focus on basic nutrition principles, nutrition assessment, the role of nutrition in health, interdisciplinary teamwork in nutrition, and the provision of nutrition counseling.

There are notable differences among countries regarding the recommendations for nutrition education. For example, the curriculum guidelines in the USA have evolved to be prescriptive and detailed, whereas the standards of the WFME used in the Republic of Ireland do not specify any nutritionrelated recommendations for medical education. The detailed and extensive USA curricula serve as a strength, as they allow for specified competency assessment. In contrast, a lack of specified competencies in the WFME standards diminishes the importance placed on medical nutrition and its application to patient care. ${ }^{27}$

There are also notable differences in the expression of curriculum guidelines among countries. For example, the Australia and New Zealand nutrition curriculum framework specifies that all medical graduates should be able to identify nutritional risk, deficits, and excesses, ${ }^{24}$ which are likely to encompass many components, including nutrition screening, anthropometric assessment, and dietary intake assessment. This broad approach is a strength of the Australia and New Zealand draft nutrition curriculum framework. ${ }^{24}$ In contrast, the UK and USA curriculum guidelines articulate some specific skills in body weight assessment, which may preclude consideration of other assessment components essential to providing competent and safe nutrition care to patients. ${ }^{4,12,14}$ Lack of clarity in the recommendations and implicit assumptions of skills may lead to confusion when translating curriculum guidelines into curriculum content. This could be addressed by a standardized assessment of competencies. Currently, the number of specific nutrition competencies assessed using OSCEs is limited by the use of standardized patients. However, the development of online assessment methods with interactive exercises, gaming environments, and virtual patient encounters to provide reproducible standardized results are becoming available and could be used in the six countries. ${ }^{28}$

At present, the only mandated nutrition-related curriculum guidelines for the reviewed countries are from the GMC in the UK, which occurs through the accreditation of medical schools. ${ }^{29}$ The GMC have also endorsed, but not mandated, the nutrition recommendations of the Academy of Medical Royal Colleges. ${ }^{14}$ Similarly, in the USA, the LCME have endorsed, but not mandated, the nutrition recommendations of the AAMC.${ }^{16}$ Lack of mandatory enforcement means that guidelines may not be incorporated in a consistent manner at medical schools within a country, limiting assumptions about the nutrition competence of doctors based on the doctors' country of origin. Lack of mandatory enforcement also illustrates a likely initial challenge to achieving a common nutrition curriculum across all reviewed countries. Agreement by all six countries would be required for the development of a generic nutrition curriculum that would enable each country to incorporate its own cultural identity; this would be followed by curriculum accreditation by the respective medical education regulatory organizations.

The USA is the only country among the six countries reviewed that mandates a national examination for a medical license. This examination includes nutrition-related items. In the UK, the GMC Shape of Training review ${ }^{30}$ has recommended discontinuing the preregistration year (Foundation Year 1) after training and granting full registration at the point of graduation. Currently, there is a growing lobby to apply the existing non-European Union graduate licensing examination to all UK/European Union graduates, which incorporates nutritional aspects under endocrinology, metabolism, and gastroenterology. This poses a new opportunity for nutrition to be integrated into the licensing assessment, and it may subsequently promote additional learning experiences throughout undergraduate medical education in these countries. ${ }^{30}$

Consideration is required as to the means by which medical schools measure the nutritional competence of students. While some components of the nutrition guidelines are discrete and easily measured - such as knowledge of the energy content of macronutrients - others require ongoing development, such as nutrition counseling skills. Effective nutrition counseling by doctors is ideally measured through improvements in patients' dietary intake ${ }^{31}$ and consequent improvements in health outcomes - both of which are challenging to measure as one assessment item. It is therefore important that medical graduates continue to develop their nutrition competence in postgraduate training and in practice.

The importance of interprofessional health education has been recognized at a global level., ${ }^{5,28}$ Nutrition curriculum guidelines from the USA, Australia, and New Zealand include specific goals for developing competence within interprofessional teams. ${ }^{10,21}$ A weakness in the UK curriculum guidelines is that similar goals are not included, suggesting that doctors from this country may require additional support to effectively work in interprofessional teams to appropriately address nutrition in patient care. There are ongoing activities 
in the promotion of nutrition competence within the evolving curricula of health care professionals, ${ }^{2}$ which represent a time of opportunity for nutrition education within medical curricula; ${ }^{28}$ these would need to be addressed if a common nutrition curricula is to be adopted.

Multinational workforces have the potential to influence the nutrition competencies of doctors within a given country. For example, in New Zealand, over $52 \%$ of registered doctors obtained their primary medical qualification overseas, with high migration from the UK (23\% of registered doctors), South Africa (5\% of registered doctors), India (3\% of registered doctors), and Sri Lanka (1\% of registered doctors). ${ }^{32}$ For doctors who come from the countries reviewed in this paper, a "Competent Authority" pathway exists where doctors are presumed to have equivalent knowledge and skills, and they are not required to sit an examination. ${ }^{32}$ However, many doctors migrate from other countries where there are clear differences in education, language, and health needs. ${ }^{32}$ This indicates the need for a broad approach to the review of medical nutrition education and further supports the use of standardized assessment as a means of ensuring competence in nutrition.

Historically, the six countries reviewed in this paper share a common language and many food customs. For example, early migrants from the UK to the USA, Canada, Australia, and New Zealand followed their traditional food customs that reflected their historical association with the rural environment, and may have included meat, bread, and dairy products. ${ }^{33}$ Today, the foods eaten in each country reflect the impact of successive waves of migrants from throughout the world to each country. ${ }^{33}$ While doctors from the six countries reviewed could be able to identify and have general nutrition knowledge of food choices from the other five countries, differences may exist in the food choices and nutrition knowledge received in undergraduate medical education for migrant doctors from other countries.

Consideration is required as to whether enhanced nutrition education at the undergraduate level will impact the complex biopsychosocial and political issues related to poor nutrition and obesity. For example, while the nutrition curriculum guidelines in the USA are detailed and prescriptive, the USA also experiences one of the highest rates of poor nutrition behavior and obesity in the world, and the projected targets for the reduction in the numbers of overweight and obese people are unlikely to be met. ${ }^{34}$ It may be that an increased focus on public health and nutrition advocacy within the curriculum is also required. Successful public health campaigns led by doctors have centered on smoking cessation ${ }^{35}$ and on bariatric surgery in carefully selected subjects. ${ }^{36}$

\section{Conclusion}

In conclusion, there are promising developments in nutrition guidelines for medical schools in the USA, Canada, the UK, the Republic of Ireland, Australia, and New Zealand. Differences in the scope and approach of nutrition-related curriculum guidelines may influence the nutrition education provided to medical students, and they may also affect the subsequent care provided by doctors in these countries. Notably, the reviewed curriculum guidelines focus on undergraduate education, and it is recognized that medical students will further enhance clinical practice competencies in nutrition during postgraduate training, depending on the specialty they enter. Consideration is required as to how to best monitor and evaluate the nutrition competence of doctors, and how nutrition competence influences patients' nutrition behavior and health outcomes. Given the comparable tertiary education systems, continuing medical education programs, language of delivery, and health care needs of populations in the reviewed countries, a joint international strategic approach to medical nutrition education would promote uniform content and may minimize duplication of effort and resources in this area, and warrants further consideration.

\section{Disclosure}

The authors report no conflicts of interest in this work.

\section{References}

1. World Medical Association. WMA Statement on Medical Education. Ferney-Voltaire, France: World Medical Association; 2006.

2. EAPC Task Force on Medical Education. Curriculum in Palliative Care for Undergraduate Medical Education: Recommendations of the European Association for Palliative Care. Milan, Italy: European Association for Palliative Care; 2007.

3. Behavioural and Social Sciences Teaching in Medicine (BeSST) Psychology Steering Group. A Core Curriculum for Psychology in Undergraduate Medical Education. Manchester, UK: Higher Education Academy Psychology Network and Subject Centre for Medicine, Dentistry and Veterinary Medicine; 2010.

4. Royal College of Physicians. Nutrition and Patients: A Doctor's Responsibility. Report of a Working Party of the Royal College of Physicians. London, UK: Royal College of Physicians; 2002.

5. World Health Organization. Global Status Report on Non-Communicable Diseases 2010. Geneva, Switzerland: World Health Organization; 2010.

6. Adams KM, Kohlmeier M, Powell M, Zeisel SH. Nutrition in medicine: nutrition education for medical students and residents. Nutr Clin Pract. 2010;25(5):471-480.

7. Gray J, editor. Nutrition in Medical Education: Report of the British Nutrition Foundation's Task Force on Clinical Nutrition. London, UK: British Nutrition Foundation; 1983. 
8. National Heart, Lung, and Blood Institute, Division of Cardiovascular Sciences. Working Group on Future Directions for Implementing Nutrition across the Continuum of Medical and Health Professions Education and Training, and Research. Bethesda, MD: National Heart, Lung, and Blood Institute; 2012.

9. World Health Organization. WHO Technical Report Series 916: Diet, Nutrition and the Prevention of Chronic Diseases. Geneva, Switzerland: World Health Organization; 2003.

10. Ball L, Desbrow B, Leveritt M. An exploration of individuals' preferences for nutrition care from Australian primary care health professionals. Aust J Prim Health. 2014;20(1):113-120.

11. Bringing physician nutrition specialists into the mainstream: rationale for the Intersociety Professional Nutrition Education Consortium. Am J Clin Nutr. 1998;68(4):894-898.

12. Curriculum Committee of the Nutrition Academic Award Program. Nutrition Curriculum Guide for Training Physicians: Practice Behavior Skills and Attitudes Across the Curriculum. Bethesda, MD: National Heart, Lung, and Blood Institute; 2002.

13. Essentials of nutrition education in medical schools: a national consensus. American Medical Student Association's Nutrition Curriculum Project. Acad Med. 1996;71(9):969-971.

14. ICGN Undergraduate Nutrition Education Implementation Group. UK Undergraduate Curriculum in Nutrition. London, UK: Academy of Medical Royal Colleges; 2013.

15. The Need for Nutrition Education/Innovation Programme [webpage on the Internet]. Global Innovation Panel (GIP). Cambridge, UK: The Need for Nutrition Education/Innovation Programme; 2014. Available from: http://www.nnedpro.org.uk/wordpress/nnedpro-global-2/. Accessed August 25, 2014.

16. Association of American Medical Colleges. Tomorrow's Doctors, Tomorrow's Cures. Washington, DC: Association of American Medical Colleges; 2007.

17. Committee on Nutrition Medical Education, Food and Nutrition Board, Council on Life Sciences, National Research Council. Nutrition Education in US Medical Schools. Washington, DC: National Academies Press; 1985.

18. National Nutrition Monitoring and Related Research Act 1990, US Public Law: 101-445; 1990.

19. Pearson TA, Stone EJ, Grundy SM, McBride PE, Van Horn L, Tobin BW; NAA Collaborative Group. Translation of nutritional sciences into medical education: the Nutrition Academic Award Program. Am J Clin Nutr. 2001;74(2):164-170.

20. Hark LA. Lessons learned from nutrition curricular enhancements. Am J Clin Nutr. 2006;83(4):968S-970S

21. Dimaria-Ghalili RA, Edwards M, Friedman G, et al. Capacity building in nutrition science: revisiting the curricula for medical professionals. Ann N Y Acad Sci. 2013;1306:21-40.
22. General Medical Council. Tomorrow's Doctors: Outcomes and Standards for Undergraduate Medical Education. London, UK: General Medical Council; 2009.

23. World Federation for Medical Education, Association of Medical Schools in Europe International Task Force. WFME Global Standards for Quality Improvement in Medical Education: European Specifications for Basic and Postgraduate Medical Education and Continuing Professional Development. Copenhagen, Denmark: University of Copenhagen; 2007.

24. Medical School Accreditation Committee. Standards for Assessment and Accreditation of Primary Medical Programs by the Australian Medical Council 2012. Kingston, Australia: Australian Medical Council Limited; 2012.

25. Medical Deans Australia and New Zealand, Health Workforce Australia. Medical Graduate Competency Framework Stage 2 Final Report Sydney, Australia: Medical Deans Australia and New Zealand; 2012.

26. Deakin University School of Medicine and School of Exercise and Nutrition Sciences Faculty of Health. Nutrition Knowledge and Competency Framework for Medical Graduates (Draft for Consultation). Melbourne, Australia: Deakin University; 2013.

27. Walker WA. Innovative teaching strategies for training physicians in clinical nutrition: an overview. J Nutr. 2003;133(2):541S-543S.

28. Kushner RF, Van Horn L, Rock CL, et al. Nutrition education in medical school: a time of opportunity. Am J Clin Nutr. 2014;99(Suppl 5): $1167 \mathrm{~S}-1173 \mathrm{~S}$

29. General Medical Council. Tomorrow's Doctors. Recommendations on Undergraduate Medical Education. London, UK: General Medical Council; 2003.

30. General Medical Council. Shape of Training. London, UK: General Medical Council; 2014.

31. Ball L, Johnson C, Desbrow B, Leveritt M. General practitioners can offer effective nutrition care to patients with lifestyle-related chronic disease. J Prim Health Care. 2013;5(1):59-69.

32. Medical Council of New Zealand. Annual Report 2012. Wellington, New Zealand: Medical Council of New Zealand; 2012.

33. Davidson A. The Oxford Companion to Food. 3rd ed. Oxford, UK: Oxford University Press; 2014.

34. Kolasa KM, Rickett K. Barriers to providing nutrition counseling cited by physicians: a survey of primary care practitioners. Nutr Clin Pract. 2010;25(5):502-509.

35. Richards D, Toop L, Brockway K, et al. Improving the effectiveness of smoking cessation in primary care: lessons learned. $N \mathrm{Z} \mathrm{Med} \mathrm{J}$. 2003;116(1173):U417.

36. Mann JI, Coppell KJ. Obesity revisited, yet again. N Z Med J. 2013; 126(1386):6-8.
Advances in Medical Education and Practice

\section{Publish your work in this journal}

Advances in Medical Education and Practice is an international, peerreviewed, open access journal that aims to present and publish research on Medical Education covering medical, dental, nursing and allied health care professional education. The journal covers undergraduate education, postgraduate training and continuing medical education

\section{Dovepress}

including emerging trends and innovative models linking education, research, and health care services. The manuscript management system is completely online and includes a very quick and fair peer-review system. Visit http://www.dovepress.com/testimonials.php to read real quotes from published authors. 